\title{
Health Indicators for Older Sexual Minorities: National Health Interview Survey, 2013-2014
}

\author{
Christina N. Dragon, MSPH, ${ }^{1}$ Alison M. Laffan, $\mathrm{PhD}^{2}$, Erkan Erdem, $\mathrm{PhD}^{3}$, Sean R. Cahill, $\mathrm{PhD}^{4}$ \\ Daniel Kenefick, Jiahui Ye, MS, and Samuel C. Haffer, $\mathrm{PhD}^{1}$
}

\begin{abstract}
Purpose: Advances in lesbian, gay, and bisexual (sexual minority [SM]) acceptance and equality have been made in the past decade. However, certain SM subgroups continue to be disadvantaged due to lack of data and, thus, lack of knowledge about these populations. Data for older sexual minorities are especially lacking and will be increasingly important as more sexual minorities enter older age. This research explores results from a nationally representative health survey to elucidate some health indicators for older sexual minorities.

Methods: Data from the 2013 and 2014 National Health Interview Surveys (NHIS) were pooled for increased sample size, and established research methods were followed as recommended by prior NHIS sexual orientation studies. We conducted descriptive analyses on the differences between SM and heterosexual groups, aged 65 years and older, for 12 health indicators.

Results: Four out of the 12 health indicators were significantly different for sexual minorities, and three out of those four indicated positive health outcomes or behaviors when compared with heterosexuals. Sexual minorities were more than three times as likely to receive HIV testing as heterosexual peers. Sexual minorities were more likely to receive an influenza vaccination, and much more likely to report excellent or very good health, than their heterosexual peers. Sexual minorities were more than twice as likely to report binge drinking, which is consistent with prior research for adult sexual minorities.

Conclusion: This analysis is the first to examine national data on health indicators for sexual minorities, aged 65 years and older, using NHIS data. As more surveys begin to collect SM data and more years of data are collected by NHIS, a clearer picture of the health of older adult sexual minorities should emerge.
\end{abstract}

Keywords: aging, lesbian, gay, and bisexual, NHIS, older adults, sexual minority.

\section{Introduction}

N 2014, THE Centers for Disease Control and Prevention (CDC) National Center for Health Statistics (NCHS) released the first report from the National Health Interview Survey (NHIS) on sexual minority (SM) data for the U.S. population aged 18 years and older. ${ }^{1}$ This publication was the result of several years of effort following the recommendations of the Institute of Medicine to ask a sexual orientation question on a nationally representative survey for all adults. ${ }^{2}$ However, this first analysis from NCHS did not examine older adults as a separate subgroup of the SM population. With this in mind, we undertook this analysis to provide a supplement on older adults using the first 2 years of NHIS SM data.

The United States is experiencing a demographic shift, with the aging population making up a larger segment of the total population and utilizing more health services due to increased life expectancy. The U.S. Census Bureau estimates that by the year 2050, the population aged 65 years and older will reach 83.7 million, nearly double what it was estimated at in 2012. ${ }^{3}$ Sixty-five years is the eligibility age for Medicare coverage and, thus, it is used by the Census, other federal agencies, and some researchers as a cutoff point to define older adults.

Most research on sexual minorities, including from the NHIS SM data, has focused on adults aged 18 and older

\footnotetext{
${ }^{1}$ Office of Minority Health, Centers for Medicare \& Medicaid Services, Baltimore, Maryland.

${ }^{2}$ Health Care Department, NORC at the University of Chicago, Bethesda, Maryland.

${ }^{3}$ Economic \& Valuation Services, KPMG LLP, McLean, Virginia.

${ }^{4}$ The Fenway Institute, Fenway Health, Boston, Massachusetts.
}

(C) Christina N. Dragon et al. 2017; Published by Mary Ann Liebert, Inc. This is an Open Access article distributed under the terms of the Creative Commons Attribution License, which permits unrestricted use, distribution, and reproduction in any medium, provided the original work is properly cited. 
(without specific analysis of those aged 65 and older), examined same-sex couples aged 65 years and older instead of using self-reported sexual orientation, or focused on results from state-level surveys. ${ }^{1,4-8}$ Prior research on the older SM population has focused on several different age brackets. A common grouping is age 50 years and older, possibly due to American Association of Retired Persons (AARP's) age eligibility cutoff for when some Americans might start to retire. ${ }^{6}$ The age 50 cutoff has also been utilized in some National Institute on Aging surveys and research, possibly to track trends of an aging population more effectively. ${ }^{9}$ Using a lower age cutoff, as well as combining multiple years of data, has improved statistical reliability due to larger sample sizes being used for analysis. With few data sources available for examining the health of older sexual minorities, significant gaps remain. ${ }^{10}$

Prior research on older sexual minorities indicates that there are differences by sex for some health outcomes and other health indicators. ${ }^{8}$ However, there are some negative trends for sexual minorities regardless of sex. We aimed at discerning whether those negative trends persisted, subsided, or were exacerbated in older age groups.?

\section{Methods}

\section{Data overview}

The NHIS is an annual survey conducted by the CDC NCHS to monitor the health of the U.S. population. ${ }^{11}$ Starting in 2013, the NHIS has collected information on the sexual orientation of the respondents, allowing researchers to investigate potential differences in health indicators between heterosexual and SM (defined as lesbian, gay, and bisexual respondents) groups. The NHIS employs a complex sampling strategy designed to produce estimates that are representative of the U.S. population; details of the design, sampling strategy, and weighting can be found elsewhere. ${ }^{12}$ NHIS collects race and ethnicity data following guidance from the U.S. Census Bureau. ${ }^{12}$

The number of respondents and response rates for the NHIS vary from year to year. For this analysis, we used the adult sample component of the survey. For this component, one adult is randomly selected from each household to complete survey questions on health-related behaviors, healthcare service utilization, healthcare access, and disability-related items, among other health-related questions. In 2013, the conditional response rate for the adult sample component was $81.7 \%$, corresponding to 34,557 adults, and in 2014 these values were $80.5 \%$ and 36,697 , respectively. ${ }^{11,13,14}$

We then limited our analysis to respondents aged 65 years and older, leaving 7732 respondents (22.4\% of the adult sample component) in 2013 and 8644 (23.6\%) in 2014. We choose to examine this age group because 65 is the age at which most individuals become eligible for Medicare.

\section{Sexual majority and minority populations}

We categorized respondents into three groups: sexual majority (hereafter: heterosexual), SM, and unknown. Respondents were asked about their sexual orientation by using the question "which of the following best represents how you think of yourself." ${ }^{15}$ Response options were: "gay" (for male respondents); "lesbian or gay" (for female respondents); "straight, that is, not gay" (male respondents); "straight, that is, not lesbian or gay" (female respondents); "bisexual"; "something else";
"I don't know the answer"; or refused. Respondents who provided a response of "gay," "lesbian or gay," or "bisexual" were combined into a single SM group to increase sample size for analysis. Respondents who provided a response of "straight, that is, not gay" or "straight, that is, not lesbian or gay" comprised the heterosexual group. All other responses were combined into an unknown category and were not included in this analysis $(n=576,3.6 \%)$.

\section{Health outcomes parameters}

We investigated the 12 health indicators available in the weighted 2013-2014 NHIS data ${ }^{13,14}$ comparing the heterosexual population with the SM population. The selected outcomes are similar to those used in the National Health Statistics Report and include health status, health-related behaviors, healthcare service utilization, and healthcare access. ${ }^{1}$ The functional limitations, visual impairment, and hearing impairment were added to our analysis, in divergence from the NCHS report on sexual orientation data, as a proxy for disability-related measures and they are often included specifically for older adult populations. Measures of health insurance status were omitted because this population, aged 65 years and older, was assumed to be covered by Medicare and disability measures were added because of their relevance to the health and well-being of older populations. All 12 health indicators derived from the NHIS are described in Table 1.

\section{Statistical analysis}

To test the statistical significance of the difference between the SM and heterosexual groups, we used a Pearson's chisquare test adjusted for the complex sample design of the NHIS. The estimates, confidence intervals, and statistical tests were computed from weighted 2013 and 2014 NHIS survey years. Estimates were weighted according to guidelines published by the NHIS. ${ }^{12}$ Sample weights from each year were divided by two, given that 2 years of data were pooled.

Because there are relatively few respondents who identify as an SM, the tests we performed have limited power, and the detectable differences are correspondingly large. For certain outcomes with very small samples sizes or low response rates, we determined that there were insufficient data to draw a conclusion. This determination was made based on the size of the standard error relative to the point estimate and by using rules recommended by CDC for reliability of estimates. ${ }^{16}$ Outcomes where the standard error was more than $30 \%$ of the point estimate for the SM group were not included in tests of statistical significance. These outcomes were hearing impairment, psychological distress, and failing to obtain needed medical care. We used Stata version 13 (StataCorp LLC, College Station, TX) for all data processing and statistical tests. We assumed that each of the statistical tests was independent and considered $P$-values less than 0.05 to be statistically significant. This research was exempt from Institutional Review Board review because it uses aggregate de-identified public use data.

\section{Results}

In the combined 2013-2014 NHIS, there were 15,800 respondents aged 65 years and older, of whom 147 respondents $(0.90 \%)$ identified as an SM. These included $68(0.88 \%)$ of the 2013 sample (7732 respondents aged 65 years and older) and $79(0.91 \%)$ of the 2014 sample (8644 respondents 
Table 1. Description of Selected Health Indicators-2013 and 2014 National Health Interview Survey

\begin{tabular}{|c|c|}
\hline Health indicator & Description \\
\hline $\begin{array}{l}\text { Excellent/very good } \\
\text { self-rated health }\end{array}$ & $\begin{array}{l}\text { Response of "excellent" or "very good" to the question "Would you say your health in general is } \\
\text { excellent, very good, good, fair, or poor?" }\end{array}$ \\
\hline $\begin{array}{l}\text { Psychological } \\
\text { distress }\end{array}$ & $\begin{array}{l}\text { Composite score of } 13 \text { or greater on a six-item scale asking about symptoms of psychological } \\
\text { distress in the past } 30 \text { days. Response codes }(0-4) \text { for each item of: so sad that nothing could } \\
\text { cheer you up, nervous, restless or fidgety, hopeless, worthless, and that everything was an effort } \\
\text { were summed to create a scale with a range of } 0-24 \text {. }\end{array}$ \\
\hline Obesity & Calculated body mass index from self-reported height and weight greater than or equal to $30 \mathrm{~kg} / \mathrm{m}^{2}$. \\
\hline $\begin{array}{l}\text { Current cigarette } \\
\text { smoker }\end{array}$ & $\begin{array}{l}\text { Respondents reporting smoking cigarettes either every day or on some days among those who had } \\
\text { smoked more than } 100 \text { cigarettes in their lifetime. }\end{array}$ \\
\hline Binge drinking & $\begin{array}{l}\text { Report of, on at least } 1 \text { day in the past year, drinking five (for men) or more alcoholic beverages } \\
\text { among those who had at least } 12 \text { drinks in their lifetime. In } 2014 \text {, the wording of this item } \\
\text { changed to differentiate binge drinking definitions by gender. Men are asked about five drinks or } \\
\text { more, whereas women are now asked about four or more drinks. }\end{array}$ \\
\hline Influenza vaccine & $\begin{array}{l}\text { Respondent report of an influenza vaccination, either via injection or nasal spray any time in the } \\
\text { past } 12 \text { months. }\end{array}$ \\
\hline $\begin{array}{l}\text { Ever been tested } \\
\text { for HIV }\end{array}$ & $\begin{array}{l}\text { The next question is about the test for HIV, the virus that causes AIDS. Except for tests you may } \\
\text { have had as part of blood donations, have you ever been tested for HIV? }\end{array}$ \\
\hline $\begin{array}{l}\text { Has a usual source } \\
\text { of medical care }\end{array}$ & $\begin{array}{l}\text { Respondents reporting they have a place they usually go to when they are sick or need advice about } \\
\text { their health that is not the hospital emergency room. }\end{array}$ \\
\hline $\begin{array}{l}\text { Failed to obtain } \\
\text { needed medical } \\
\text { care }\end{array}$ & $\begin{array}{l}\text { Report of not getting needed care because the respondent was unable to afford it. Separate items } \\
\text { asked about the following types of care: prescription medicines, mental healthcare or counseling, } \\
\text { dental care (including check-ups), eyeglasses, to see a specialist, and follow-up care. }\end{array}$ \\
\hline $\begin{array}{l}\text { Functional } \\
\text { limitations }\end{array}$ & $\begin{array}{l}\text { Reporting difficulty in carrying out any of the following activities without using any special } \\
\text { equipment: walk a quarter of a mile-about three city blocks; walk up } 10 \text { steps without resting; } \\
\text { stand or be on your feet for about } 2 \text { hours; sit for about } 2 \text { hours; stoop, bend, or kneel; reach up } \\
\text { over your head; use your fingers to grasp or handle small objects; lift or carry something as heavy } \\
\text { as } 10 \text { pounds such as a full bag of groceries; push or pull large objects like a living room chair; go } \\
\text { out to things like shopping, movies, or sporting events; participate in social activities such as } \\
\text { visiting friends, attending clubs and meetings, going to parties; do things to relax at home or for } \\
\text { leisure (reading, watching TV, sewing, listening to music). }\end{array}$ \\
\hline Visual impairment & Reported trouble seeing, even when wearing glasses or contact lenses. \\
\hline Hearing impairment & Self-reported history of ever using a hearing aid(s) in the past. \\
\hline
\end{tabular}

Table 1 indicates the NHIS items and their definitions that were selected to reflect the 12 health indicators that were investigated. NHIS, National Health Interview Survey.

aged 65 years and older). The majority of the respondents in the SM group identified as gay or lesbian $(n=111)$, and the remaining 36 identified as bisexual. Table 2 shows the demographic characteristics of the SM and heterosexual groups. On average, the SM respondents were younger $(P<0.001)$ and less likely to be female $(P=0.011)$ than their heterosexual respondent counterparts. Self-reported race and ethnicity distributions were similar for heterosexual and SM respondents. Compared with heterosexual respondents, SM respondents were less likely to be married and had lower total household income $(P<0.001$ for both).

\section{Health outcomes}

Table 3 shows the population percentages for the selected health-related indicators for both SM and heterosexual groups. For most indicators, no statistically significant differences were detected. However, for four of the indicatorsself-rated excellent/very good health, influenza vaccination, HIV testing, and binge drinking behavior-significant differences were observed.

SM respondents were more likely than heterosexual respondents to report that they are in excellent or very good health $(62.7 \%$ and $45.9 \%$, respectively, $P=0.003)$, have received an influenza vaccine during the past year $(79.7 \%$ and $68.8 \%$, respectively, $P=0.023)$, and have ever been tested for HIV (51.3\% and $15.8 \%$, respectively, $P<0.001)$. Having five or more alcoholic drinks in 1 day at least once in the past year, an indicator of binge drinking, was also more likely among SM respondents compared with heterosexual respondents ( $14.5 \%$ and $6.7 \%$, respectively, $P=0.003$ ).

For functional limitations, the difference was relatively large between the heterosexual and SM groups (64.0\% and $53.4 \%$, respectively), although this difference did not reach statistical significance. Similar proportions of SM and heterosexual older adults were obese, reported being a current cigarette smoker, having a usual source of medical care, and having a visual impairment. The remaining indicators-psychological distress, failing to obtain needed medical care, and hearing impairment-were not tested for statistical significance due to a relative standard error greater than $30 \%$ of the estimate, which is not considered to produce reliable inferences.

\section{Discussion}

Using the same analytic tools as the NCHS, our results indicate that challenges persist with small sample sizes, which impede understanding of the SM adult population aged 65 
Table 2. Older Adult Respondents BY GROUP, NHIS 2013-2014

\begin{tabular}{|c|c|c|c|}
\hline \multicolumn{4}{|c|}{ 2013-2014 NHIS } \\
\hline & $\begin{array}{l}\text { Sexual } \\
\text { minority }\end{array}$ & Heterosexual & $\mathrm{P}$ \\
\hline Number of respondents & 147 & 15,653 & \\
\hline Female, \% & 38.38 & 55.80 & 0.011 \\
\hline Male, \% & 61.62 & 44.20 & \\
\hline \multicolumn{4}{|l|}{ Race } \\
\hline White, \% & 90.59 & 87.16 & 0.227 \\
\hline Black, \% & 6.75 & 8.75 & \\
\hline Asian, \% & 2.66 & 4.09 & \\
\hline \multicolumn{4}{|l|}{ Ethnicity } \\
\hline Hispanic, \% & 7.86 & 7.58 & 0.666 \\
\hline Non-Hispanic, \% & 92.14 & 92.42 & \\
\hline \multicolumn{4}{|l|}{ Household income } \\
\hline$\$ 0-\$ 34,999$ per year, $\%$ & 47.55 & 39.37 & $<0.001$ \\
\hline $\begin{array}{l}\$ 35,000-\$ 74,999 \\
\text { per year, \% }\end{array}$ & 24.78 & 30.14 & \\
\hline $\begin{array}{l}\$ 75,000-\$ 99,999 \\
\text { per year, \% }\end{array}$ & 9.49 & 7.89 & \\
\hline$\$ 100,000$ and more, $\%$ & 12.58 & 12.34 & \\
\hline Undefined/unknown, \% & 5.60 & 10.26 & \\
\hline \multicolumn{4}{|l|}{ Marital status } \\
\hline $\begin{array}{l}\text { Married-spouse } \\
\text { in household, \% }\end{array}$ & 27.54 & 55.68 & $<0.001$ \\
\hline $\begin{array}{l}\text { Married-spouse } \\
\text { not in household, \% }\end{array}$ & 4.01 & 1.11 & \\
\hline Widowed, \% & 7.48 & 25.88 & \\
\hline Divorced, \% & 17.31 & 10.76 & \\
\hline Separated, \% & 0.56 & 1.05 & \\
\hline Never married, $\%$ & 32.68 & 3.79 & \\
\hline Living with partner, $\%$ & 9.87 & 1.58 & \\
\hline Unknown, \% & 0.55 & 0.14 & \\
\hline Age, mean $\pm S D$ & $71.8 \pm 0.5$ & $73.8 \pm 0.1$ & $<0.001$ \\
\hline
\end{tabular}

years and older. ${ }^{1}$ Our analysis indicates that heavy alcohol consumption continues to stand out as a negative health behavior, which is higher in SM older adults compared with heterosexual older adults. ${ }^{8,17}$ Similarly, heightened alcohol consumption has been found in sexual minorities across the life course. ${ }^{1}$ Although our analysis was unable to test for differences between lesbian and bisexual women, there is evidence to support that when more data are available lesbians would likely have a higher rate of excessive drinking than bisexual or heterosexual women. ${ }^{8,18}$ The long-term and complex side effects from heavy or binge alcohol use throughout the life course can lead to increased health issues in older populations, including decreased life expectancy. ${ }^{19}$

Interestingly, our analysis did not detect a difference between older sexual minorities and their heterosexual peers in reported current cigarette smoking, obesity, usual sources of medical care, visual impairment, and functional limitations. Psychological distress, failing to obtain needed medical care, and hearing impairment were not tested for statistical significance due to already small and unreliable estimates. Psychological distress is an indicator that often comes up for older adults, especially sexual minorities, as they adjust to limited physical functionality, changing social circumstances, and the stress of adjusting to the aging process. ${ }^{18,20}$ Continued investigation as more years of data become available, along with more complex multivariate analysis, should elucidate why our research was unable to detect statistically significant differences.

Older sexual minorities appear to fare better on preventive health measures such as ever having obtained an HIV test and receiving an influenza vaccine in the past year. The results for HIV testing may be influenced by adult sexual minorities in other NHIS analyses: $51 \%$ for older sexual minorities compared with $69 \%$ for gay/lesbian individuals and $54 \%$ for bisexual individuals aged $18-64$, respectively. ${ }^{1}$ It is interesting that heterosexual older adults have a substantially lower

Table 3. Estimated Population Values for Select Health Outcomes, People 65 Years of Age and Older, by Sexual Orientation-2013 and 2014 NHIS

\begin{tabular}{|c|c|c|c|c|c|}
\hline Health outcome/indicators & $\begin{array}{l}\text { Gay/lesbian, } \\
\%(S E)\end{array}$ & $\begin{array}{c}\text { Bisexual, } \\
\%(S E)\end{array}$ & $\begin{array}{c}\text { Sexual minority, } \\
\%(S E)\end{array}$ & $\begin{array}{l}\text { Heterosexual, } \\
\quad \%(S E)\end{array}$ & $\mathrm{P}$ \\
\hline Sample size & 111 & 36 & 147 & 15,653 & \\
\hline Population size estimate $^{\mathrm{a}}$ & 310,077 & 96,380 & 406,457 & $42,228,575$ & \\
\hline $\begin{array}{l}\text { Excellent/very good } \\
\text { self-rated health }\end{array}$ & $62.29(6.18)$ & $63.87(11.05)$ & $62.66(5.42)$ & $45.89(0.54)$ & 0.003 \\
\hline Psychological distress & $4.20(2.24)$ & $2.48(2.14)$ & $3.79(1.78)$ & $2.37(0.16)$ & - \\
\hline Obesity & $29.74(5.86)$ & $21.14(7.54)$ & $27.70(4.87)$ & $26.74(0.50)$ & 0.843 \\
\hline Current cigarette smoker & $8.88(2.84)$ & $9.66(5.12$ & $9.07(2.51)$ & $8.57(0.31)$ & 0.836 \\
\hline Binge drinking & $13.75(3.86)$ & $17.06(9.28)$ & $14.54(3.68)$ & $6.66(0.31)$ & 0.003 \\
\hline Influenza vaccination & $78.23(5.09)$ & $84.38(6.50)$ & $79.69(4.13)$ & $68.77(0.54)$ & 0.023 \\
\hline HIV testing & $52.47(7.00)$ & $47.27(12.69)$ & $51.25(5.96)$ & $15.81(0.42)$ & $<0.001$ \\
\hline Usual source of medical care & $95.46(2.44)$ & $98.30(1.72)$ & $96.13(1.91)$ & $96.62(0.19)$ & 0.193 \\
\hline Failed to obtain needed medical care & $3.94(2.54)$ & $6.00(3.72)$ & $4.43(2.11)$ & $2.34(0.16)$ & - \\
\hline Functional limitations & $53.22(6.50)$ & $54.03(13.34)$ & $53.41(5.92)$ & $64.04(0.54)$ & 0.193 \\
\hline Visual impairment & $16.00(4.74)$ & $18.97(8.66)$ & $16.71(4.15)$ & $13.83(0.37)$ & 0.813 \\
\hline Hearing impairment & $2.22(2.10)$ & $3.35(3.26)$ & $2.49(1.78)$ & $3.04(0.18)$ & - \\
\hline
\end{tabular}

Percentages are estimated population percentages, accounting for the survey design, and standard errors are provided in parentheses. $P$-values are from a Pearson's chi-squared test of differences between the sexual minority and heterosexual groups assuming independence across health indicators. $P$-values for estimates with a relative standard error greater than $30 \%$ were not calculated and are indicated by a dash.

${ }^{\mathrm{a}}$ Population estimates are generated by using the final survey weights provided in NHIS data files, which account for the survey design, nonresponse, and poststratification adjustments (e.g., age, race, and sex distributions of the U.S. population). 
rate of ever having received an HIV test, at $\sim 15 \%$ compared with $42 \%$ in the 18 - to 64 year-old heterosexual population. ${ }^{1}$

Older sexual minorities also report substantially higher rates of excellent or very good health compared with their older heterosexual peers. In younger adult populations, the gap between sexual minorities and heterosexuals in terms of self-rated excellent or very good health is much less pronounced. ${ }^{1}$ It is unclear as to whether this response is the result of persistent resilience among older sexual minorities or that older heterosexuals experience a decrease in perceived good health. ${ }^{18,21}$

\section{Limitations}

In this analysis of the 2013-2014 NHIS data, we combined gay, lesbian, and bisexual older adult respondents into a single group due to the small number of older SM respondents. However, prior literature in the elderly and nonelderly populations suggests that there may be important differences between each group and/or between genders. When we examined gay, lesbian, and bisexual respondents separately, we observed some differences that we would expect based on previous research, but none of these differences were statistically significant and, thus, they were excluded from our results. We did not find significant differences between gay, lesbian, and bisexual respondents, most likely due to the small sample sizes for each of the groups. Other studies that were able to examine differences between by gender or differences between gay, lesbian, and bisexual groups combined more years of data than we had available at the time of our analysis. ${ }^{6-8}$ Further, in some cases where there may be differences between gay, lesbian, and bisexual older adult groups, combining groups will conceal differences with the heterosexual group. It is possible that subgroup differences could be observed with more data. As more years of NHIS data become available, we will be able to discern trends more effectively, and move beyond the limitations of bivariate analysis.

In statistical testing, we assumed each comparison was independent and considered $P$-values less than 0.05 as indicating statistically significant findings. If instead, we do not assume independence, and correct for multiple comparisons, the threshold for statistical significance would decrease to $P<0.006$. Using this threshold would imply that the difference for influenza vaccination is statistically insignificant.

In addition, it was challenging to explore differences between other demographic variables for older sexual minorities with only 2 years of data. Future research should include multivariable analysis and explore the influence of socioeconomic and other demographic factors on these health indicators for older sexual minorities.

\section{Conclusion}

Our objective of providing an analysis of NHIS sexual orientation data on health indicators for older sexual minorities, to supplement the work published by NCHS, was accomplished. We were able to show that self-reported excellent or very good overall health persists into older ages for sexual minorities and that health behaviors such as HIV testing and receiving influenza vaccines also continue. We also found that alcohol consumption continues to be an issue for older sexual minorities. These findings are important to the field of SM health research because, although limited, they provide a nationally representative supplement to the work of the NCHS that focused on the adult population aged 18-64. ${ }^{1}$ Continued analysis is needed as more years of data become available, and the population aged 18-64 years, for which data were reported previously, ages into the Medicare population.

\section{Acknowledgments}

The authors thank Josef Clift, DrPH, for his insight and editorial review of this article and Erin Ewald for additional statistical consultation. This work was supported by the Centers for Medicare \& Medicaid Services under Contract Number HHSM-500-2011-00002I with NORC at the University of Chicago.

\section{Disclaimers}

The views expressed in this article are those of the authors and do not necessarily represent the views of the Centers for Medicare \& Medicaid Services or the U.S. Department of Health and Human Services. Portions of this work appear in the CMS OMH data highlight. ${ }^{22}$

\section{Author Disclosure Statement}

No competing financial interests exist.

\section{References}

1. Ward BW, Dahlhamer JM, Galinsky AM, Joestl SS: Sexual orientation and health among U.S. adults: National Health Interview Survey, 2013. Natl Health Stat Report 2014;(77):1-10.

2. Institute of Medicine (US) Committee on Lesbian, Gay, Bisexual, and Transgender Health Issues and Research Gaps and Opportunities: The Health of Lesbian, Gay, Bisexual, and Transgender People: Building a Foundation for Better Understanding. Washington (DC): National Academies Press (US), 2011.

3. Ortman JM, Velkoff VA, Hogan H: An aging nation: The older population in the United States. Economics and Statistics Administration, U.S. Department of Commerce, U.S. Census Bureau 2014; Report Number: P25-1140:1-28.

4. Gonzales G, Przedworski J, Henning-Smith C: Comparison of health and health risk factors between lesbian, gay, and bisexual adults and heterosexual adults in the United States: Results from the National Health Survey. JAMA Intern Med 2016;176:1344-1351.

5. Dahlhamer J, Galinsky A, Joestl S: Sexual orientation in the 2013 National Health Interview Survey: A quality assessment. Vital Health Stat 2 2014;(169):1-32.

6. Gonzales G, Henning-Smith C: Disparities in health and disability among older adults in same-sex cohabiting relationships. J Aging Health 2015;27:432-453.

7. Wallace SP, Cochran SD, Durazo EM, Ford CL: The health of aging lesbian, gay and bisexual adults in California. Policy Brief UCLA Cent Health Policy Res 2011;(PB2011-2):1-8.

8. Fredriksen-Goldsen KI, Kim HJ, Barkan SE, et al.: Health disparities among lesbian, gay, and bisexual older adults: Results from a population-based study. Am J Public Health 2013;103:1802-1809.

9. Fredriksen-Goldsen KI: Resilience and disparities among lesbian, gay, bisexual, and transgender older adults. Public Policy Aging Rep 2011;21:3-7.

10. Fredriksen-Goldsen KI, Muraco A: Aging and sexual orientation: A 25-year review of the literature. Res Aging 2010;32: $372-413$. 
11. Centers for Disease Control and Prevention. About the National Health Interview Survey. 2016. Available at www.cdc .gov/nchs/nhis/about_nhis.htm Accessed February 20, 2017.

12. Parsons VL, Moriarity C, Jonas K, et al.: Design and estimation for the National Health Interview Survey, 2006-2015. Vital Health Stat 2 2014;(165):1-53.

13. Division of Health Interview Statistics, National Center for Health Statistics, Centers for Disease Control and Prevention, U.S. Department of Health and Human Services. 2013 National Health Interview Survey (NHIS) Public Use Data Release: Survey Description. 2014. Available at ftp:// ftp.cdc.gov/pub/health_statistics/NCHS/dataset_documentation/NHIS/2013/srvydesc.pdf Accessed March 20, 2017.

14. Division of Health Interview Statistics, National Center for Health Statistics, Centers for Disease Control and Prevention, U.S. Department of Health and Human Services. 2014 National Health Interview Survey (NHIS) Public Use Data Release: Survey Description. 2015. Available at https://ftp.cdc .gov/pub/Health_Statistics/NCHs/Dataset_Documentation/ NHIS/2014/srvydesc.pdf Accessed March 20, 2017.

15. Division of Health Interview Statistics, National Center for Health Statistics, Centers for Disease Control and Prevention, U.S. Department of Health and Human Services. 2013 National Health Interview Survey (NHIS) Public Use Data Release: A Brief Quality Assessment of the NHIS Sexual Orientation Data. 2014. Available at www.cdc.gov/nchs/data/ nhis/qualityso2013508.pdf Accessed March 20, 2017.

16. National Center for Health Statistics, Centers for Disease Control and Prevention: Ambulatory Health Care Data, Questionnaires, Datasets, and Related Documentation. Reliability of estimates. Available at www.cdc.gov/nchs/ahcd/ahcd_ estimation_reliability.htm Accessed February 9, 2017.
17. Bryan AE, Kim HJ, Fredriksen-Goldsen KI: Factors associated with high-risk alcohol consumption among LGB older adults: The roles of gender, social support, perceived stress, discrimination, and stigma. Gerontologist 2017;57(Suppl 1): S95-S104.

18. Choi SK, Meyer IH: LGBT Aging: A Review of Research Findings, Needs, and Policy Implications. Los Angeles: The Williams Institute, 2016.

19. Gonzales K, Roeber J, Kanny D, et al.: Alcohol-attributable deaths and years of potential life lost-11 states, 20062010. MMWR Morb Mortal Wkly Rep 2014;63:213-216.

20. Boehmer U, Miao X, Linkletter C, Clark MA: Health conditions in younger, middle, and older ages: Are there differences by sexual orientation? LGBT Health 2014;1:168-176.

21. Fredriksen-Goldsen KI, Kim HJ, Emlet CA, et al.: The Aging and Health Report: Disparities and Resilience Among Lesbian, Gay, Bisexual, and Transgender Older Adults. Seattle, WA: Institute for Multigenerational Health, 2011.

22. Centers for Medicare \& Medicaid Services Office of Minority Health, the Fenway Institute, KPMG, and NORC: Health disparities experienced among older sexual minorities: National Health Interview Survey, 2013-2014. CMS OMH Data Highlight No. 5. Baltimore, MD, 2016.

Address correspondence to: Christina N. Dragon, MSPH Office of Minority Health Centers for Medicare \& Medicaid Services 7500 Security Boulevard, Mailstop: S2-12-17 Baltimore, MD 21244-1850

E-mail: christina.dragon@cms.hhs.gov 